\title{
Management of house fly, Musca domestica L. (Muscidae: Diptera), through botanical baits
}

\author{
Hira Afzal ${ }^{1}$, Sohail Ahmed ${ }^{1 *}$, Rashad Rasool Khan ${ }^{1}$, Muhammad Sufian ${ }^{1}$, \\ Muhammad Arshad ${ }^{1}$, Muhammad Qasim²* \\ ${ }^{1}$ University of Agriculture, Department of Entomology, Faisalabad-38040, Pakistan. \\ ${ }^{2}$ Zhejiang University, Institute of Insect Sciences, College of Agriculture E'Biotechnology, Key Lab of Molecular Biology of Crop \\ Pathogens and Insects, Hangzhou 310058, China.
}

\section{A R T I C L E I N F O}

\section{Article history:}

Received 07 July 2019

Accepted 25 October 2019

Available online 09 April 2020

Associate Editor: Ana Campos

\section{Keywords:}

Biological control

Plant extracts

Synthetic insecticides

Disease vector

\begin{abstract}
A B S T R A C T
The house fly, Musca domestica L. (Diptera: Muscidae), is a major pest of all aspects of life, like the domestic, medical and veterinary and causal agent of several pathogenic diseases. The present study was conducted to evaluate the potential of different insecticide-free baits against house fly by incorporating flower methanol extract of Helianthus annuus (sunflower) and Tegetes erecta (marigold) at 10\%, 20\% and 30\% bait formulation of corn syrup, dried milk and water. However, imidacloprid and thiacloprid (each at $5 \%$ concentration) were also included in the study for comparison. Results showed that insecticide baits were superior in causing mortality of adult house fly but dependent upon syrup. Overall, $20 \%$ baits of both extracts caused more than half population death of house fly within $48 \mathrm{~h}$. On the other hand, the mortality rate by $30 \%$ baits (from sunflower and marigold) had a similar impact as observed in case of imidacloprid and thiacloprid baits. Therefore, biological baits could play a more active and safer role in the management of house fly as compared to synthetic insecticides.
\end{abstract}

\section{Introduction}

Insecticides resistance in the house fly, Musca domestica L. (Muscidae: Diptera), is a global issue and hinders successful control of the pest (Levchenko et al., 2018; Meisel and Scott, 2018). Various food sources are available for house fly in different habitats (Hung et al., 2015). Baits are the best option in these diverse environments for attraction. Various plant extracts have been tested in bait formulation against house fly management, though results are encouraging. Plant extracts and volatile oils were not comparable with insecticides (Kamel et al., 2019). Repellent and toxic actions of these extracts have been reported against house flies (Attaullah et al., 2019; Baana et al., 2018). Sunflower (Helianthus annuus) leaf surfaces and anthers produce secondary compounds (Prasifka et al., 2015) that are secreted into glandular trichomes, may offer defense against herbivorous insects [reviewed in (Aartsma et al., 2017; Hussain et al., 2019)]. Insecticidal properties of aerial and floral parts of Marigold ( Tegetes spp.) have also been reported [reviewed in (Walia et al., 2017)], and it is deterrent to insect pests (Ali et al., 2016; Diabate et al., 2019).

\footnotetext{
* Corresponding author.

E-mail: cmqasimgill@zju.edu.cn (M. Qasim); cmqasimgill@zju.edu.cn (M. Qasim).
}

Sugar is phagostimulant for house flies, however, with development of taste aversion-related behavioral resistance in house fly (Burgess and King, 2017), high caloric sweeteners have been suggested for inclusion in baits against house fly (Fisher et al., 2017). Corn syrup is another alternative to replace low caloric sugar (Bernklau et al., 2018), and its phagostimulant property is not well established. Studies with other sugary materials have demonstrated differences in effectiveness in baits, like solutions of molasses that were more attractive to house flies than honey, maple syrup, or jaggery (date palm sugar) (Geden et al., 2009).

Keeping in view the properties of sunflower and marigold leaf toxic compounds, and high fructose corn syrup, the present work was focused to assess the impact of plant extract incorporated baits against field populations of the house fly.

\section{Materials and Methods}

\section{House fly collection and rearing}

The present study was conducted in the Toxicology Laboratory, Department of Entomology, University of Agriculture, Faisalabad, Pakistan (2018-2019). Adult house flies were collected from various 
sources, like dairy, poultry farms and chicken shops, and were kept in rearing cages provided with the wheat bran, milk powder and brewers' yeast mixture in a diet (Ahmed et al., 2005) for mass rearing.

\section{Bait preparation}

Three types of corn-glucose syrups (directly taken from Maize processing Mills, and their sweetness was performed through Refractometer on the basis of Brix) were obtained from Rafhan Maize Products Ltd. Faisalabad, used in the baits (Table 1). Fully bloomed flowers of marigold ( Tagetes erecta) and sunflower (Helianthus annuus) were plucked from mature plants, dried under shade, ground to a powder form and sieved through 60 mesh. Powder of each flower was mixed with methanol (80\%) in 1:2 ratio in glass bottles, which were thoroughly shaken on a rotary shaker. The mixture was then filtered through Whatman Filter (No. 42) and the solvent was evaporated in Soxhlet apparatus (Shangai Heqi Glassware Co., Ltd.). The final solid material was dissolved in methanol (Fisher Scientific UK) and stored in brown-colored bottles. A partially pure mixture of each flower extract

Table 1

Formulations of plant extracts / insecticides.

\begin{tabular}{|c|c|c|}
\hline Extract/Insecticide & Syrup bait group & Concentration (\%) \\
\hline \multirow[t]{9}{*}{ Marigold } & A & 10 \\
\hline & & 20 \\
\hline & & 30 \\
\hline & B & 10 \\
\hline & & 20 \\
\hline & & 30 \\
\hline & C & 10 \\
\hline & & 20 \\
\hline & & 30 \\
\hline \multirow[t]{9}{*}{ Sunflower } & A & 10 \\
\hline & & 20 \\
\hline & & 30 \\
\hline & B & 10 \\
\hline & & 20 \\
\hline & & 30 \\
\hline & C & 10 \\
\hline & & 20 \\
\hline & & 30 \\
\hline \multirow[t]{3}{*}{ Imidacloprid } & A & 0.5 \\
\hline & B & \\
\hline & C & \\
\hline \multirow[t]{3}{*}{ Thiacloprid } & A & 0.5 \\
\hline & B & \\
\hline & C & \\
\hline
\end{tabular}

$\mathbf{A} ; \mathbf{B}=($ Sweet and sticky $), \mathbf{C}=($ Sticky $)$. was diluted with bait formula (syrup + dry milk powder + plant extract) to make final concentrations of $10 \%, 20 \%$ and $30 \%$. Since corn syrup resists granulation after making baits of flower extract, the mixture was spread on a tray, and stainless steel wire gauze was laid over mixture which was allowed to solidify in an oven running at $100{ }^{\circ} \mathrm{C}$. The resultant solids were then used as bait. In the case of insecticides, the final concentration was $0.5 \%$.

\section{Bioassay}

A total of 50 house flies were released in the plastic jars with the prepared baits at the bottom, and the mouth of jars was covered with the muslin cloth for proper aeration and to prevent fly escape. Along with bait, sugar feed (total weight $12 \mathrm{~g}$ ) was also placed in jars. Jars were kept under the room temperature and relative humidity. Mortality of house flies was recorded in the jars for $6 \mathrm{~h}, 12 \mathrm{~h}, 24 \mathrm{~h}$ and $48 \mathrm{~h}$. However, results of $48 \mathrm{~h}$ in the form of cumulative mortality have been presented.

\section{Statistical analysis}

All of the treatments (two extracts and their three concentrations and one control; two insecticides at one concentration) were arranged in Completely Randomized Design in five replications. Mortality data were subjected to full factorial ANOVA, and means were compared with Tukey's HSD test to find out difference among flower and insecticide concentration, time, syrups and their interactions.

\section{Results}

ANOVA (Table 2) showed that interaction between time and treatment and treatment and syrups were significant $(\mathrm{P} \leq 0.05)$, whereas three-way interaction among time, treatments and syrups was non-significant $(\mathrm{P} \geq 0.05)$.

Mean percent mortality of house fly exposed to flower extracts and insecticides in corn syrups after $48 \mathrm{~h}$ is shown in Table 3. Corn syrup bait with insecticides had the highest mortality in syrup A as compared to the other two syrups. Plant extracts had lower mortality than insecticides and were significantly different from insecticide treatments. However, plant extract at the highest concentration (30\%) caused more than $50 \%$ mortalities in $48 \mathrm{~h}$, and this trend had gradually increased for both plant extracts (Table 3 ).

\section{Mortality by sunflower-extract vs synthetic insecticides}

The overall highest mortality was reached up to $68.00 \pm 2.80 \%$ in syrup-A-bait by sunflower-extract (30\%), followed by syrup-C-bait with $63.60 \pm 0.40 \%$ mortality of house fly, and least mortality was

Table 2

Analysis of Variance for mortality in different tests.

\begin{tabular}{|c|c|c|c|c|c|}
\hline Source & df & SegSS & Adj MS & $\mathrm{F}$ & $\mathrm{P}$ \\
\hline Time (A) & 3 & 34147.8 & 11382.6 & 184.3 & $<0.01$ \\
\hline Treatments (B) & 7 & 64272.1 & 9181.7 & 148.6 & $<0.01$ \\
\hline Syrups (C) & 2 & 5387.8 & 2693.9 & 43.61 & $<0.01$ \\
\hline$A \times B$ & 21 & 6606.6 & 314.6 & 5.09 & $<0.01$ \\
\hline$A \times C$ & 6 & 4155.5 & 692.6 & 51.21 & 0.14 \\
\hline $\mathrm{B} \times \mathrm{C}$ & 14 & 1235.8 & 88.3 & 1.43 & $<0.01$ \\
\hline$A \times B \times C$ & 42 & 2042.8 & 48.6 & 10.79 & 0.82 \\
\hline Error & 384 & 23720.6 & 61.8 & & \\
\hline Total & 479 & 141568.9 & & & \\
\hline
\end{tabular}

$S=7.85954 R-S q=83.24 \% R-S q(\operatorname{adj})=79.10 \%$. 
Table 3

Comparison of mean percent mortality $( \pm$ SE) of housefly exposed to flower extracts and insecticides in corn syrups after $48 \mathrm{~h}$.

\begin{tabular}{|c|c|c|c|}
\hline \multirow{2}{*}{$\begin{array}{c}\text { Insecticide / plant extract } \\
(\%)\end{array}$} & \multicolumn{3}{|c|}{ Kinds of Syrups } \\
\hline & Syrup A & Syrup B & Syrup C \\
\hline Imidacloprid 0.5 & $78.4 \pm 1.8 \mathrm{a}$ & $67.7 \pm 1.7 c$ & $70.1 \pm 2.3 \mathrm{bc}$ \\
\hline Thiacloprid 0.5 & $77.7 \pm 2.0 \mathrm{ab}$ & $65.5 \pm 1.6 \mathrm{~cd}$ & $67.9 \pm 2.5 c$ \\
\hline Sunflower 10 & $45.7 \pm 4.7 \mathrm{ijk}$ & $35.4 \pm 2.61$ & $39.4 \pm 2.9 \mathrm{kl}$ \\
\hline Sunflower 20 & $55.1 \pm 3.3 c-h$ & $46.9 \pm 1.9 \mathrm{~h}-\mathrm{k}$ & $50.3 \pm 2.6 g-j$ \\
\hline Sunflower 30 & $68.0 \pm 2.8 c$ & $57.4 \pm 1.7 \mathrm{~d}-\mathrm{g}$ & $63.6 \pm 0.4 \mathrm{cde}$ \\
\hline Marigold 10 & $43.6 \pm 3.5 \mathrm{jkl}$ & $39.3 \pm 2.0 \mathrm{kl}$ & $43.4 \pm 5.4 \mathrm{jkl}$ \\
\hline Marigold 20 & $54.3 \pm 3.4 \mathrm{f}-\mathrm{i}$ & $52.0 \pm 1.3 g-j$ & $54.9 \pm 2.2 \mathrm{e}-\mathrm{h}$ \\
\hline Marigold 30 & $69.2 \pm 2.7 b c$ & $62.3 \pm 1.5 \mathrm{c}-\mathrm{f}$ & $65.6 \pm 2.3 c d$ \\
\hline
\end{tabular}

Values are mean \pm SE. Means with same letters in rows and columns are not significantly different from other at $\alpha<0.05$.

observed from syrup-B-bait. On the other hand, imidacloprid caused maximum mortality up to $78.40 \pm 1.81 \%$ in syrup-A-bait, while least mortality $(65.52 \pm 1.63 \%)$ from synthetic insecticides was observed by thiacloprid in syrup-B-bait. Overall, a significant mortality variation was observed between plant extracts and synthetic insecticides as well as among different syrup baits (Table 3 ).

\section{Mortality by marigold-extract vs synthetic insecticides}

The same trend of mortality was noted by marigold-extract and synthetic insecticides. Highest mortality by plant extract was $69.2 \pm 2.7 \%$ in syrup-A-bait (30\%) whereas least mortality by plant extract was recorded up to $62.3 \pm 1.5 \%$ from syrup-B-bait. As compared to plant extract, the mortality rate was higher by synthetic insecticides in all types of syrup baits. However, mortality variation had a significant range between plant extract and synthetic insecticides as well as among different syrup baits (Table 3 ).

\section{Discussion}

The present work compared plant extracts with insecticide baits (imidacloprid and thiacloprid) and showed insecticides being the most effective. However, the development of insecticide resistance (Levchenko et al., 2018) and safety of the insecticide baits in a habitat (like kitchen/livestock sheds) highlights the need for an alternative to these insecticides. It is the first development to assess the potential of plant extract-formulated baits, containing syrup to lure house flies. All baits of synthetic insecticides and 30\% extract revealed high mortality of house flies ( $>60 \%-70 \%$ ) within 48 h exposure. Overall, mortality observations of all treatments were more attractive to manage house flies. However, sweet and sticky baits of all formulations were more effective as compared to sweet less bait.

Efficacy of plant extracts as adulticide for the management of house flies has been established (Attaullah et al., 2019; Chauhan et al., 2018). Sugar contents are attractive to insects, and play a vital role in the success of a bait. Sugar cane, for example, is a general ingredient in the baits for house flies (Burgess and King, 2016). However, commercial baits have no equal ability to attract and trap house flies effectively (Hamid et al., 2016). Brown sugar and palm sugar (less in fructose) were ingredients in some formulations which had varied catches of house flies individually (Zahn et al., 2019).

The syrup-based results of current work are in accordance with the findings of Zhang et al. (2010) who reported that sucrose had the most potent stimulatory effect on the feeding of Helicoverpa armigera. Similarly, Wada-Katsumata et al. (2011) also shed light on the vital importance of the glucose as an attractant for wild-type cockroaches, but it adequately deterred feeding in a glucose-averse strain. Moreover, Seraydar and Kaufman (2015) demonstrated the evolution of consumption irritancy- or taste aversion-related behavioral resistance in the house fly, which was proved in another study (Burgess and King, 2016) where repeated exposure to sucrose-based bait resulted in the evolution of sucrose-feeding avoidance. Though high caloric sugar (sucrose) increases survival and longevity of house flies (Fisher et al., 2017), but caloric equivalence can be obtained from corn syrup to avoid aversion from sucrose.

On the other hand, plant extract-based results of this study have the same trend to the previous studies against house flies, especially with respect to exposure time and extract concentration. Attaullah et al. (2019) revealed that the effectiveness of plant extracts had increased with the increment of time as well as concentration. The mortality rate was reached up to two-third of the population within three days at the maximum concentration of Penganum harmala.

Imidacloprid and thiacloprid are neonicotinyl insecticides and are reported to be toxic to mosquito vectors, house fly and horse fly. Unfortunately, neonicotinyl insecticides have been implicated in colony disorder of honeybees and are not recommended for baits. Recent report in Pakistan by Abbas et al. (2015) also showed no resistance of house flies to imidacloprid at recommended field dose. Thus, plant extracts have a good potential to be developed into an effective, all-around, natural larvicidal, pupicidal and oviposition deterrent agent for completely controlling house fly population, especially at their breeding and oviposition sites. Most importantly, being much safer to humans and biodegradable in the environment much than neonicotinyl, extracts can disrupt all stages of house fly life cycle and effectively reduce the whole of its population, hence they can help reduce all serious diseases vectored by house flies to human beings.

\section{Conclusion}

Plants extracts have significant potential to control house fly populations in different formulations of syrup baits. A concentrated plant extract could cause the highest mortality up to the impact of synthetic insecticides. Moreover, high fructose corn syrup could be alternative under these circumstances, and its effectiveness in the present study was evidenced owing to house flies feeding on corn syrup bait in the presence of insecticide/plant extract free sucrose.

\section{Acknowledgments}

This project was funded by the funding of Rafhan Maize Products (Co. Ltd.), Faisalabad, Pakistan. 


\section{Conflicts of interest}

The authors declare no conflicts of interest.

\section{Author's contributions}

Conceptualization: Sohail Ahmed, Rashad Rasool Khan

Experimentation: Hira Afzal, Muhammad Sufian

Analysis: Hira Afzal and Muhammad Qasim

Writing-original draft: Hira Afzal, Sohail Ahmed, Muhammad

Arshad, Muhammad Qasim

Writing-review and editing: Rashad Rasool Khan, Muhammad Sufian

Funding acquisition: Sohail Ahmed

\section{References}

Aartsma, Y., Bianchi, F. J., van der Werf, W., Poelman, E. H., Dicke, M., 2017. Herbivore-induced plant volatiles and tritrophic interactions across spatial scales. New Phytol. 216 (4), 1054-1063.

Abbas, N., Shad, S. A., Shah, R. M., 2015. Resistance status of Musca domestica L. populations to neonicotinoids and insect growth regulators in Pakistan poultry facilities. Pak. J. Zool. 47 (6), 1663-1671.

Ahmed, S., Zia, K., Akhtar, I., 2005. Responses of house fly, Musca domestica L. to a baiting system. Int. J. Agric. Biol. 7, 424-426.

Ali, A., Tabanca, N., Amin, E., Demirci, B., Khan, I. A., 2016. Chemical composition and biting deterrent activity of essential oil of Tagetes patula (Marigold) against Aedes aegypti. Nat. Prod. Commun. 11 (10), 1535-1538.

Attaullah, Zahoor, M. K., Zahoor, M. A., Mubarik, M. S., Rizvi, H., Majeed, H. N., Zulhussnain, M., Ranian, K., Sultana, K., Imran, M., Qamer, S., 2019. Insecticidal, biological and biochemical response of Musca domestica (Diptera: Muscidae) to some indigenous weed plant extracts. Saudi J. Biol. Sci. 26, 281-285.

Baana, K., Angwech, H., Malinga, G. M., 2018. Ethnobotanical survey of plants used as repellents against housefly, Musca domestica L. (Diptera: Muscidae) in Budondo Subcounty, Jinja District, Uganda. J. Ethnobiol. Ethnomed. 14 (1), 35.

Bernklau, E. J., Hibbard, B. E., Bjostad, L. B., 2018. Sugar preferences of western corn rootworm larvae in a feeding stimulant blend. J. Appl. Entomol. 142 (10), 947-958.

Burgess, E. R., King, B. H., 2016. Behavior and survival of the filth fly parasitoids Spalangia endius and Urolepis rufipes (Hymenoptera: Pteromalidae) in response to three granular house fly baits and components. Environ. Entomol. 45 (6), 1496-1504.

Burgess, E. R., King, B. H., 2017. Insecticidal potential of two sugar alcohols to Musca domestica (Diptera: muscidae). J. Econ. Entomol. 110 (5), 2252-2258.

Chauhan, N., Malik, A., Sharma, S., 2018. Repellency potential of essential oils against housefly, Musca domestica L. Environ. Sci. Pollut. Res. Int. 25 (5), 4707-4714.

Diabate, S., Martin, T., Murungi, L. K., Fiaboe, K. K. M., Subramanian, S., Wesonga, J., \& Deletre, E., 2019. Repellent activity of Cymbopogon citratus and Tagetes minuta and their specific volatiles against Megalurothrips sjostedti. J. Appl. Entomol. In press. https://doi. org/10.1111/jen.12651.

Fisher, M. L., Fowler, F. E., Denning, S. S., Watson, D. W., 2017. Survival of the house fly (Diptera: Muscidae) on Truvia and other sweeteners. J. Med. Entomol. 54 (4), 999-1005.

Geden, C. J., Szumlas, D. E., Walker, T. W., 2009. Evaluation of commercial and field-expedient baited traps for house flies, Musca domestica L.(Diptera: muscidae). J. Vector Ecol. 34 (1), 99-103.

Hamid, M. S., Daud, A., Mohamed, S. B., Mohamad, N. M., Rashid, M. A. 2016. A comparative study on different baits used to attract house fly in Malaysia. Int. J. Adv. Sci. Eng. Inf. Technol. 6 (5), 588-593.

Hung, K. Y., Michailides, T. J., Millar, J. G., Wayadande, A., Gerry, A. C., 2015. House fly (Musca domestica L.) attraction to insect honeydew. PLoS One 10 (5), e0124746.

Hussain, M., Debnath, B., Qasim, M., Bamisile, B. S., Islam, W., Hameed, M. S., Wang, L., Qiu, D., 2019. Role of saponins in plant defense against specialist herbivores. Molecules 24 (11), 2067.

Kamel, A. A., Mohamed, M. B. E. D., El-Dakhly, K. M., 2019. Larvicidal activity and bio-efficacy of some products against larvae of the Housefly, Musca domestica (L)(Diptera: muscidae). J. Appl. Sci. (Faisalabad) 19 (5), 427-433.

Levchenko, M. A., Silivanova, E. A., Bikinyaeva, R. K., Balabanova, G. F., 2018. Efficacy of acetamiprid and fipronil fly baits against the housefly (Musca domestica L.) under laboratory conditions. Vet. World 11 (7), 953-958.

Meisel, R. P., Scott, J. G., 2018. Using genomic data to study insecticide resistance in the house fly, Musca domestica. Pestic. Biochem. Physiol. 151, 76-81.

Prasifka, J. R., Spring, O., Conrad, J., Cook, L. W., Palmquist, D. E., Foley, M. E., 2015. Sesquiterpene lactone composition of wild and cultivated sunflowers and biological activity against an insect pest. J. Agric. Food Chem. 63 (16), 4042-4049.

Seraydar, K. R., Kaufman, P. E., 2015. Does behaviour play a role in house fly resistance to imidacloprid-containing baits? Med. Vet. Entomol. 29 (1), 60-67.

Wada-Katsumata, A., Silverman, J., Schal, C., 2011. Differential inputs from chemosensory appendages mediate feeding responses to glucose in wild-type and glucose-averse German cockroaches, Blattella germanica. Chem. Senses 36, 589-600.

Walia, S., Saha, S., Tripathi, V., Sharma, K. K., 2017. Phytochemical biopesticides: some recent developments. Phytochem. Rev. 16 (5), 989-1007.

Zahn, L. K., Cox, D. L., Gerry, A. C., 2019. Mortality rate of house flies (Diptera: Muscidae) exposed to insecticidal granular fly baits containing Indoxacarb, Dinotefuran, or Cyantraniliprole. J. Econ. Entomol. In press. https://doi.org/10.1093/jee/toz170.

Zhang, Y.-F., van Loon, J. J. A., Wang, C.-Z., 2010. Tarsal taste neuron activity and proboscis extension reflex in response to sugars and amino acids in Helicoverpa armigera (Hübner). J. Exp. Biol. 213 (16), 2889-2895. 